\title{
Corte de Apelaciones de Santiago "Neira Ramos Alicia con Benavides Báez Bernardo"
}

\author{
25 DE JULIO DE 2005
}

MATERIA: Responsabilidad civil - Concepto de daño moral (pretium doloris - lesión a derechos o bienes de la personalidad) - Prueba del daño moral (daños que pueden presumirse) - Avaluación del daño moral (criterios - ponderación)

\section{LEGISLACIÓN APLICABLE:}

Artículo $19 \mathrm{n}^{\circ} 3$ de la Constitución Política; 684, 1793, 1824, 1826 y 2214 del Código Civil; y 514 y 527 del Código de Procedimiento Penal.

\section{DOCTRINA:}

- La concepción que entiende al daño moral como afectación de los llamados derechos de la personalidad es la que ha permitido su reconocimiento y su posterior desarrollo dogmático, en atención a que pone el acento en la persona y en la lesión de sus atributos fundamentales.

Daño moral es aquel infligido a las creencias, los sentimientos, la dignidad, la estima social o la salud psíquica. En definitiva, aquel que se refiere al patrimonio espiritual, a los bienes inmateriales tales como la salud, el honor, la libertad y otros análogos.

- El daño moral puro consistente en el menoscabo psíquico y el dolor causado a la madre por la muerte de su hija menor, no requiere de prueba alguna.

- A fin de reducir la arbitrariedad en la determinación de las indemnizaciones por daño moral, las pautas que deben regir su reparación, son las siguientes: a) La reparación integral del daño; b) Evitar las indemnizaciones en globo y procurar una evaluación separada y fundamentada de cada una de las partidas de la indemnización; c) Creación de tablas o baremos para daños morales que permiten al juez un parámetro para fijar la indemnización; d) Consideraciones de carácter macro y macroeconómicas, es decir, el grado de desarrollo económico del país y la situación particular de la víctima y de la persona obligada; y e) Publicaciones periódicas de las indemni- 
zaciones judiciales, con lo cual se consigue obtener una información estadística que en cierto modo sirva para uniformar las decisiones en casos semejantes.

\section{Sentencia:}

Santiago, veinticinco de julio de dos mil cinco.

\section{Vistos:}

Se reproduce la sentencia en alzada de veintinueve de septiembre de dos mil uno, escrita a fojas 300 y siguientes con excepción del considerando catorce y el párrafo primero del considerando dieciséis, que se eliminan y en la parte final del decimoquinto que dice en lo que a este respecta, se sustituye esta frase por en su contra; y teniendo en su lugar y, además, presente:

1. Que el Código de Bello se inspiró en principios del derecho romano en lo que dice relación con la adquisición del dominio, es decir, que de los contratos solo nacen derechos y obligaciones para las partes que los suscriben; para adquirir el dominio es necesaria la presencia de un modo de adquirir.

2. Que del contrato de compraventa de un vehículo motorizado -cosa mueble - nace la obligación de entregar para el vendedor, es decir, debe cumplir con la tradición, la que se efectúa significando una de las partes (vendedor-tradente) a la otra (comprador-adquirente) que le transfiere el dominio y figurando esta transferencia por medios reales o simbólicos.

3. Que tratándose de vehículos motorizados por su importancia económica, la ley ha establecido un sistema registral parecido al de la propiedad inmobiliaria, eso si la inscripción en el registro de vehículos motorizados, que lleva el Servicio de Registro e Identificación, no constituye requisito, prueba ni garantía de posesión ni menos de dominio.

4. Que extrapolando estos principios doctrinarios al caso sub judice, se encuentra acreditado en autos que el camión patente DJ-8628 fue vendido por don Oscar Benavides Arismendi a don Fernando Adrián Leiva según consta de la escritura de compraventa de vehículo motorizado suscrita ante el notario don Arturo Carvajal de esta ciudad con fecha tres de enero de dos mil, no habiéndose realizado la inscripción a la fecha del accidente de tránsito que ocasionó la muerte de la menor Sabrina Leticia Madrid Neira, por el contrario, consta que el mencionado móvil quedó en poder del 
vendedor don Oscar Benavides Arismendi, quien lo entregó para conducirlo, a su pariente don Bernardo Alex Benavides Báez, lo que lleva a concluir a estos jueces que no se efectuó la tradición del vehículo camión DJ-8628 estando, en consecuencia, radicado el dominio en el vendedor don Oscar Benavides Arismendi.

5. Que sentado lo anterior, acompañado de la circunstancia de que no se realizó la correspondiente inscripción de la compraventa en el registro de vehículos motorizados a la época en que ocurrió el accidente de marras, aparece como legitimado pasivo de la acción civil de indemnización de perjuicios el demandado don Oscar Benavides Arismendi en su calidad de propietario del vehículo antes singularizado.

6. Que dándose en el caso sub lite todos los elementos que conforman la responsabilidad civil extracontractual, nace la obligación de indemnizar los perjuicios ocasionados, haciéndose indispensable razonar si corresponde acoger la acción indemnizatoria en lo que al daño moral se refiere.

7. Que no hay duda que conceptuar el daño moral es uno de los problemas más complejos de la responsabilidad civil. La dificultad no solo se da en materia extracontractual, sino que también, y en mayor proporción, en la contractual, ya que el concepto ha de ser el mismo en ambas responsabilidades. Esta dificultad se ve acentuada por la diversa nomenclatura que emplean los autores; los más lo denominan daño moral, otros daño no patrimonial o extrapatrimonial, algunos daños inmaterial y no faltan los que lo individualizan como daño no pecuniario. A su vez el daño moral puede tener consecuencias patrimoniales, lo que nos lleva a distinguir entre daño moral puro y daño moral con repercusión patrimonial. Ahora para intentar una definición, nos encontramos con concepciones negativas que recurren, para dar una noción, a contraponerlo al daño patrimonial y así señalan que daño moral es todo perjuicio cuyo objeto no es un interés patrimonial; que no afecta al patrimonio; que carece de equivalencia pecuniaria, etc. Por otra parte, corrientes positivas ponen acento en el llamado precio del dolor (Pretium doloris) es decir, el daño moral se le identifica con los dolores y turbaciones síquicas que derivan del quebranto padecido. La jurisprudencia de nuestros más altos tribunales ha recogido esta posición y ha definido el daño moral señalando que es el dolor, la aflicción el pensar en la víctima o en sus parientes más cercanos o aquel que consiste en el dolor psíquico y aun físico que se experimenta a raíz de un suceso determinado. Otra posición es aquella que considera que hay daño moral cuando afecta a los llamados derechos de la personalidad. Así dan como noción de daño moral los infligidos a las creencias, los sentimientos, la dignidad, la estima social o la salud física o 
psíquica. Estos daños en consecuencia, son aquellos que se refieren al patrimonio espiritual, a los bienes inmateriales, tales como la salud, el honor, la libertad y otros análogos. Sin duda esta es la concepción que indudablemente ha permitido el reconocimiento al daño moral y su posterior desarrollo por la dogmática, en atención a que pone el acento en la persona y a la lesión de sus atributos más caros. En el caso que nos ocupa, nos encontramos ante un daño moral puro que lo ha sufrido la actora civil, menoscabo psíquico y dolor que no requiere de prueba alguna, toda vez que se trata de la muerte de su hija menor de catorce años en circunstancias por demás trágicas.

8. Que para determinar el resarcimiento del daño y el quantum de la indemnización y dejando a un lado las discusiones dogmáticas respecto a que si la sanción civil del daño moral es una pena privada o es una reparación, simplemente debe recurrirse pragmáticamente, a todos los elementos que llevan a una indemnización que satisfaga la víctima. Siendo realista, la indemnización de un daño como el moral nunca alcanzará a cubrir la totalidad del perjuicio, por lo que su reparación deviene casi en un imposible. Sentado lo anterior, fijar el quantum de la indemnización es una tarea de por sí ardua puesto que nos estamos adentrando en un campo netamente subjetivo en que tradicionalmente se ha dicho que el juez es soberano para determinarlo, sin quedar sujeto a parámetros objetivos que le vinculen. Lo primero que salta a la vista es la falta de criterios objetivos que pudieran servir de sustento a una indemnización justa, equitativa y ecuánime; en que esté ausente la arbitrariedad, empero es de suyo complejo alcanzar la equivalencia entre la lesión a bienes morales de por sí de carácter infungible con la compensación dineraria que de por sí es esencialmente fungible. No habiendo denominador común, se presenta la imposibilidad de convertir un perjuicio moral directamente en unidades monetarias. Sin embargo, ante esta imposibilidad natural, en el derecho comparado se han ideado ciertas pautas que deben regir la reparación del daño moral. Es así que aparece como una premisa la reparación integral del daño lo que lleva ínsito toda la problemática antes esbozada, pero que como fin último de la responsabilidad civil extracontractual y contractual debe ser el ideal perseguido por el juez. Evitar las indemnizaciones en globo y procurar una evaluación separada y fundamentada de cada una de las partidas de la indemnización. Creación de tablas o baremos para daños morales que permiten al juez un parámetro para fijar la indemnización. Consideraciones de carácter macro y microeconómicas, es decir, debe estar presente en todo resarcimiento, el grado de desarrollo económico del país y la situación particular de la víctima y de la persona obligada a reparar. 
En fin, publicaciones periódicas de las indemnizaciones judiciales, con lo cual se consigue obtener una información estadística que en cierto modo sirva para uniformar las decisiones en casos semejantes. Ponderando estos jueces estas variables ajustada al mérito de los autos fijarán una indemnización por daño moral que deberán pagar solidariamente el conductor del camión y el tercero civilmente responsable, en su calidad de propietario del mencionado móvil, señores Bernardo Alex Benavides y Oscar Benavides Arismendi. Por lo razonado y lo dispuesto en los artículos 684, 1793, 1824 y 1826 del Código Civil y 514 y 527 del Código de Procedimiento Penal, se revoca la sentencia de veintinueve de septiembre de dos mil uno, escrita a fojas 300 y siguientes, en cuanto no dio lugar a la demanda de indemnización de perjuicios en contra de don Oscar Benavides Arismendi y rechaza la indemnización por daño moral en contra de don Bernardo Alex Benavides Báez y en su lugar se declara:

I. Que se condena a los demandados civilmente señores Bernardo Alex Benavides Báez y Oscar Benavides Arismendi, en su calidad de conductor del camión DJ-8628 y propietario del mismo, respectivamente, a pagar solidariamente a la actora doña Alicia Carmen Neira Ramos la suma de cincuenta millones de pesos (\$50.000.000.-) debidamente reajustados desde que esta sentencia quede ejecutoriada, más intereses a contar de la constitución en mora, con costas. Se confirma, en lo demás, la sentencia en alzada. Redacción del abogado Integrante señor Oscar Herrera Valdivia. Regístrese y devuélvase. No 90.715-2001.- Pronunciada por los Ministros de la Novena Sala, presidida por el señor Juan Araya Elizalde y conformada por el Ministro señor Mauricio Silva Cancino y el Abogado Integrante señor Oscar Herrera Valdivia. 